\title{
HENRI PIÉRON, ROBERTO MANGE E A HISTÓRIA DA PSICOTÉCNICA NO BRASIL: REPRESENTAÇÕES EM DISPUTA
}

\author{
Luciana Dadico* \\ Rogério Monteiro de Siqueira*
}

\section{RESUMO}

Este artigo discute a gênese da psicotécnica nas décadas de 1920 a 1940, analisando, de forma comparada, três cursos de psicotécnica ministrados em São Paulo: por Roberto Mange, no Liceu de Artes e Ofícios, em 1926, e na Escola Livre de Sociologia e Política de São Paulo, em 1934; e por Henri Piéron, na Escola Normal de São Paulo, em 1926. A análise aqui envidada questiona a associação causal entre psicotécnica e taylorismo, que coloca o nome de Mange ao mesmo tempo como precursor e impulsionador das ideias de Taylor no Brasil. Além disso, ela mostra que, embora estes cursos respondam a projetos locais voltados à indústria e educação, eles expressam também a materialização de um projeto global, construído sobre ferramentas estatísticas, equipamentos padronizados e circulação internacional de textos e intelectuais, com implicações para a historiografia da psicologia no período.

Palavras-chave: Henri Piéron, Roberto Mange, psicotécnica, historiografia.

\footnotetext{
* Universidade Federal de Mato Grosso (UFMT), Cuiabá/MT, Brasil.

**Universidade de São Paulo (USP), São Paulo/SP, Brasil.
} 


\title{
HENRI PIÉRON, ROBERTO MANGE Y LA HISTORIA DE \\ LA PSICOTÉCNICA EN BRASIL: REPRESENTACIONES EN DISPUTA
}

\section{RESUMEN}

Este artículo analiza la génesis de la psicotecnia en las décadas de 1920 a 1940, analizando, de manera comparativa, tres cursos de psicotecnia impartidos en São Paulo: por Roberto Mange, en el Liceu de Artes e Ofícios, en 1926, y en la Escuela Libre de Sociología y Política de São Paulo, en 1934; y de Henri Piéron, en la Escola Normal de São Paulo, en 1926. El análisis aquí presentado cuestiona la asociación causal entre psicotecnia y taylorismo, que ubica el nombre de Mange al mismo tiempo como precursor y promotor de las ideas de Taylor en Brasil. Además, muestra que, si bien estos cursos responden a proyectos locales orientados a la industria y la educación, también expresan la materialización de un proyecto global, construido sobre herramientas estadísticas, equipos estandarizados y circulación internacional de textos e intelectuales, con implicaciones para la historiografía de la psicología en el periodo.

Palabras clave: Henri Piéron, Roberto Mange, psicotécnica, historiografía.

\section{HENRI PIÉRON, ROBERTO MANGE AND THE HISTORY OF PSYCHOTECHNICS IN BRAZIL: REPRESENTATIONS IN CONTEST}

\begin{abstract}
This article discusses the genesis of psychotechnics in the 1920s and 1940s, analyzing, in a comparative way, three psychotechnics courses taught in São Paulo, Brazil: by Roberto Mange, at the Liceu de Artes e Ofícios, in 1926, and at the Escola Livre de Sociologia e Política de São Paulo, in 1934; and by Henri Piéron, at the Escola Normal de São Paulo, in 1926. The analysis presented here questions the causal association between psychotechnics and Taylorism, which places the name of Mange at the same time as a precursor and promoter of Taylor's ideas in Brazil. Furthermore, it shows that, although these courses respond to local projects aimed at industry and education, they also express the materialization of a global project, built on statistical tools, standardized equipment and international circulation of texts and intellectuals, with implications for historiography of psychology in the period.
\end{abstract}

Keywords:Henri Piéron, Roberto Mange, psychotechnics, historiography.

\section{HENRI PIÉRON, ROBERTO MANGE ET L'HISTOIRE DE LA PSYCHOTECHNIQUE AU BRÉSIL: REPRÉSENTATIONS EN CONFLIT}

\section{RESUME}

Cet article aborde la genèse de la psychotechnique dans les années 1920 et 1940, analysant, de manière comparative, trois cours de psychotechnique dispensés à São Paulo: par Roberto Mange, 
au Liceu de Artes e Ofícios, en 1926, et à l'École libre de sociologie et de politique de São Paulo, en 1934 ; et par Henri Piéron, à l'Escola Normal de São Paulo, en 1926. L'analyse présentée ici interroge l'association causale entre psychotechnique et taylorisme, qui place le nom de Mange à la fois comme précurseur et promoteur des idées de Taylor au Brésil En outre, il montre que, si ces cours répondent à des projets locaux à destination de l'industrie et de l'éducation, ils expriment aussi la matérialisation d'un projet global, construit sur des outils statistiques, des équipements standardisés et une circulation internationale de textes et d'intellectuels, avec des implications pour l'historiographie de la psychologie dans la période.

Mots-clés:Henri Piéron, Roberto Mange, psychotechnique, historiographie. 


\section{INTRODUÇÃO'}

As primeiras décadas do século $\mathrm{XX}$ foram pródigas para $\mathrm{o}$ desenvolvimento dos testes psicológicos no Brasil, aplicados nas escolas, nas fábricas, na avaliação de condutores de trens e automóveis. Essa avaliação é consensual na maioria das cronologias que tratam da história da psicologia no Brasil (WECHSLER, HUTZ, PRIMI 2019; ANTUNES, 2012; ANTUNES, 2014). Dada a centralidade que a testagem exerceu no processo de autonomização almejada para a disciplina no período, muitas pesquisas têm se voltado às obras produzidas na época, buscando caracterizar as diversas correntes de pensamento e práticas que passaram a constituir o campo da psicologia no Brasil. São exemplos dessa tendência os trabalhos sobre a obra de Lourenço Filho (MONARCHA, 2001), Medeiros e Albuquerque (GOMES, 2004; JACÓ-VILELA, 2014), Manuel Bonfim (ANTUNES, 2016), Maria Brasília Leme Lopes e Isaías Alves (JACÓ-VILELA, 2014), Mira y López (MARTINS, 2014; JACÓ-VILELA\& RODRIGUES, 2014), Helena Antipoff (CAMPOS et all, 2002), Noemy Rudolfer (MORAES 2012), entre outros.

Como materializações dessa cultura emergente, alguns impressos começam a figurar em seus frontispícios suas demarcações disciplinares. Monarcha (2001) aponta vários trabalhos nos anos 1920 e 1930 que trazem a palavra "teste" no título: O movimento dos testes, em 1925, por C. A. Baker; Teste individual da inteligência, em 1927, por Isaias Alves; O método dos testes, em 1928, por Manuel Bomfim, Testes: como medir a inteligência dos escolares, em 1931, por Celsina Faria Rocha e Bueno Andrade, e Testes ABC: para a verificação da maturidade necessária à aprendizagem da leitura e escrita, por Lourenço Filho".

Neste trabalho, ampliamos esse panorama da época, elencando obras que enunciassem em seu título também a palavra "psicotécnica”. Assim, encontramos as Notas sobre psychotechnica, de Roberto Mange, de 1926; Psychologia e

\footnotetext{
${ }^{1}$ Pesquisa financiada pela FAPESP. Processo 19/02073-1.
} 
psychotechnica, de Henri Piéron, de 1927 (Figura 1); o Estudo psychotechnico de alguns tests de aptidão, de Ulisses Pernambucano, de 1927; as notas de aula Psycotechnica, de Roberto Mange, de 1934; e Assistência psychotechnica, estudo technico do homem no trabalho, de Raul Rocha, de $1940^{2}$.

Figura 1 - Frontispícios da Psicologia e Psicotécnica (1927) de Henri Piéron e das Notas sobre Psicotécnica (1926) de Robert Mange.
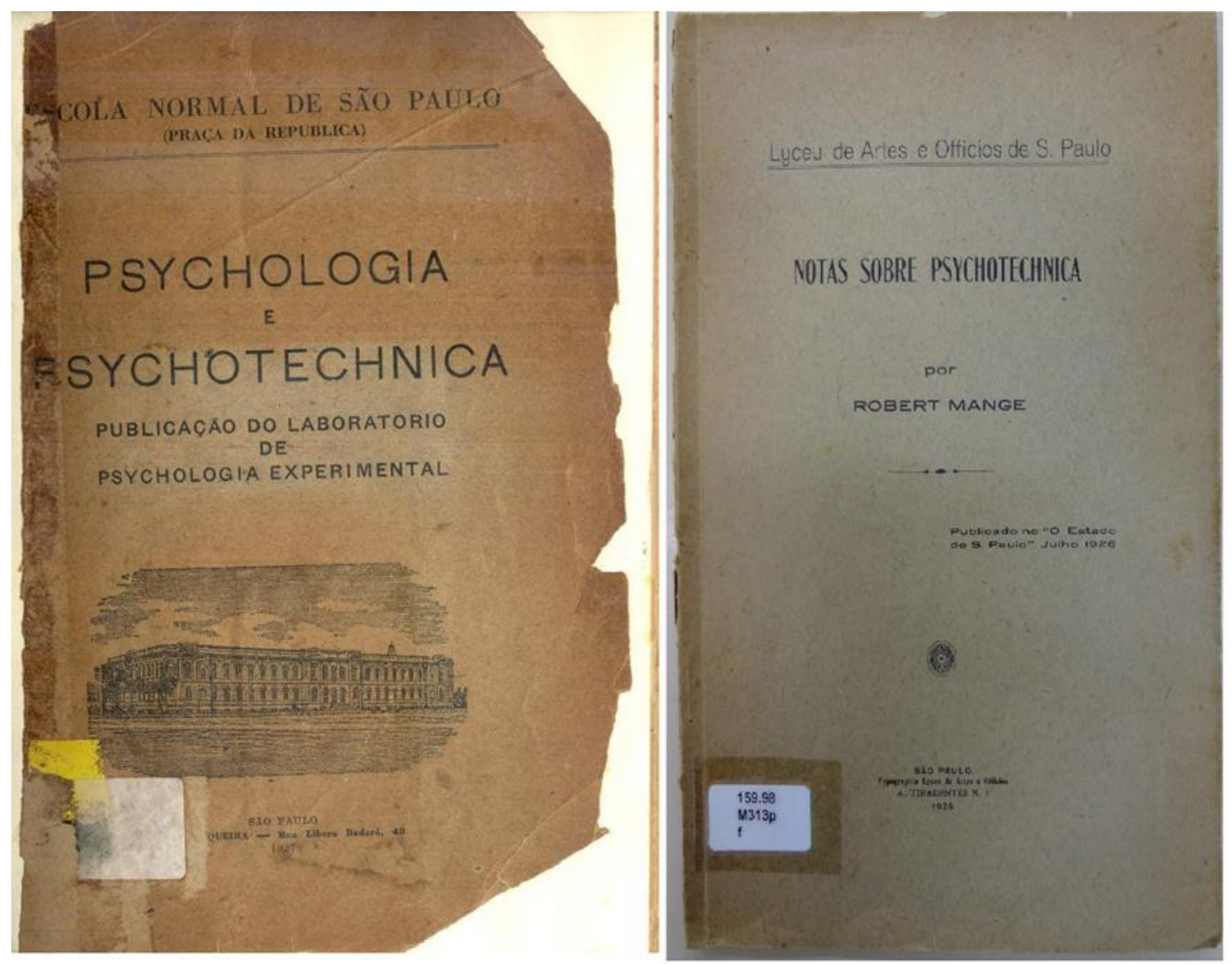

Fonte: os autores.

Dentre esses autores, Roberto Mange, no Liceu de Artes e Ofícios, em 1926, e na Escola Livre de Sociologia e Política de São Paulo, em 1934, e Henri Piéron, na Escola Normal de São Paulo, em 1926, são aqueles engajados em

\footnotetext{
2 Conforme levantamentos feitos dos termos "psychotechnica" e "psycotechnico" nas bibliotecas e acervos da Universidade de São Paulo, da Pontifícia Universidade Católica, da Universidade Estadual de Campinas e da Universidade Federal do Rio de Janeiro, nos principais jornais e periódicos da época, na antiga Escola Normal de São Paulo, no Serviço Nacional da Indústria (SENAI) e na Fundação Escola de Sociologia e Política de São Paulo (FESPSP).
} 
produzir notas de aulas e organizar uma disciplina chamada psicotécnica. No entanto, essas obras ainda não foram analisadas detalhadamente pela historiografia, sendo este o objetivo principal de nosso trabalho.

Da perspectiva da escolha das obras e dos autores a serem resenhados, e do que se procura iluminar nesse corpus, tais visadas acabam por instituir não somente um cânon para a disciplina nascente, mas modos de leitura mais controlados e homogêneos, a despeito de alguns historiadores acertadamente insistirem em dissidências nesse processo. Enquanto Isaias Alves ou Medeiros e Albuquerque, por exemplo, são tratados por Antunes (2012), como defensores do uso dos testes para classificação e exclusão, Manoel Bonfim e Pernambuco são descritos como pensadores com soluções divergentes sobre a testagem. Por outro lado, segue atual o debate sobre pertinência ou não na busca de uma identidade para a disciplina psicológica em seu processo de institucionalização (Massimi, 2008; Castro, Facchinetti \& Portugal, 2018), bem como as disputas em torno das influências nacionais, em intersecção com modelos distintos de universidade que cercam as propostas de aplicabilidade e subdivisões da matéria - com implicações para a historiografia do campo. Daí a relevância na inserção dos textos de Mange e Piéron neste cânon, para a construção de um panorama historiográfico mais complexo sobre o período.

Hoje tomada como um ramo da psicologia que se ocupa da testagem, a psicotécnica não nasceu com propósito explícito: seu escopo, usos e teorizações, eram postos à prova nas instituições e no cotidiano das pessoas na medida em que eram criados. Enquanto ingressa nos órgãos de formação brasileiros, a psicotécnica é também divulgada e apropriada, passando a embasar desde o ensino de música e o enxadrismo até a classificação de crianças em reformatórios (RETI, 1927; A QUESTÃO, 1929). O objeto da psicotécnica, assim, acaba por conformar-se aos interesses da sociedade da época. A análise comparada que apresentamos dos dois trabalhos de Roberto Mange demonstra que mesmo a obra de um único autor revela visadas distintas sobre o mesmo tema.

Objetos em construção contínua, a disciplina e a sua história conformam 
uma representação coletiva, resultantes de um "trabalho de classificação e de recorte que produz configurações intelectuais múltiplas pelas quais a realidade é contraditoriamente construída pelos diferentes grupos que compõem uma sociedade" (CHARTIER, 1991, p. 183). Não é à toa que a escolha de obras, autores e de grades de leitura, praticada inclusive em balanços historiográficos recentes (CAMPOS et al, 2010), também foi cultivada entre os fundadores da disciplina. Historiadores e praticantes operam em prol de representações coletivas, nem sempre convergentes.

Por serem textos produzidos como compilações de aulas, em cursos sobre a disciplina nascente, a análise dos trabalhos de Mange e Piéron demandam uma estratégia metodológica específica. Em primeiro lugar, importa situar a psicotécnica a partir das dinâmicas acadêmicas e do mercado de trabalho no período. A apresentação das trajetórias institucionais e os interesses pessoais de Mange e Piéron, na primeira seção deste artigo, procuram cumprir esse objetivo. Nas duas seções seguintes, adentramos nas estruturas das obras para investigar o modo como os diferentes cursos de Mange e Piéron buscam conformar tanto as bases teóricas quanto as aplicações da disciplina. Assim, constituíram termos de comparação: a) conceitos centrais (o que é a psicotécnica, inteligência ou aptidões e termos correlatos); b) relações entre psicologia e psicotécnica e destas com outras disciplinas (estatística, ergologia, filosofia, pedagogia etc); c) objetos, sujeitos, métodos, categorias e instrumentos de medidas; d) aplicações de suas propostas na escola, nas fábricas e em outras esferas da sociedade; e) visão histórica sobre a disciplina, influências teóricas (incluindo bibliografia dos cursos) e filiações nacionais. A análise das obras de dois autores contemporâneos, que trabalhavam temas próximos, mas que visavam à aplicação em ambientes inicialmente distintos, a escola e a indústria, permite discutir a existência de um corpus comum a essas duas frentes.

A vantagem em termos, da autoria de Mange, dois manuais sobre um mesmo tema - o editado pelo Liceu de Artes e Ofícios em 1924 (Figura 1) e a sebenta de 1934 - e as ementas das suas disciplinas proferidas na Escola Livre de 
Sociologia de São Paulo até os anos 1940, levam-nos a escrutinar as modificações que a disciplina sofreu no período, sobretudo após as críticas que ela recebeu em relação ao enquadramento determinista da noção de inteligência. Assim, discutese também ao longo dessas duas seções a estabilidade da disciplina em seus primeiros 20 anos, tema da quarta seção deste artigo. Uma vez analisadas as obras, discutiremos em uma última seção a recepção dos trabalhos de Mange e Piéron em alguns balanços da área, dos anos 50, e suas implicações para a historiografia da psicologia no Brasil.

\section{MANGE E PIÉRON EM SÃO PAULO}

Nas primeiras décadas do século XX, assistiu-se a um deslocamento no eixo econômico do país, acompanhando o processo de industrialização de São Paulo (SUZIGAN, 2000), motivo pelo qual os chamados "saberes psi" teriam encontrado na capital paulista usos para além dos escolares e médicopsiquiátricos predominantes no Rio de Janeiro na mesma época (CASTRO et al, 2018). A preocupação local com a formação de mão-de-obra, operária e especializada, bem como de uma elite intelectual, impulsionou não apenas a empresa escolanovista em prol da educação, mas também a fundação de escolas, faculdades e da Universidade de São Paulo, em 1934, de modo que cursos ministrados por estrangeiros na capital federal aportaram também na cidade de São Paulo.

Henri Piéron já havia ministrado um curso de psicotécnica no Rio de Janeiro em 1923, na Policlínica Geral, por iniciativa do Instituto de Alta Cultura do Rio de Janeiro. A vinda de Piéron a São Paulo seguiu-se à fundação do Instituto Técnico Franco-Paulista, em 1925, que se tornara o principal órgão da colaboração acadêmica entre França e Brasil e seria a instituição responsável por patrocinar o curso sobre psicotécnica ministrado na Escola Normal de São Paulo em 1926 (PETITJEAN, 1996, p. 106-107). De acordo com Antunes (2012), nessa época inicia-se o movimento dos testes no Brasil, e as Escolas Normais 
constituem importante substrato para seu desenvolvimento.

Piéron é lembrado hoje como um dos fundadores da psicologia científica. Com formação em Filosofia e Ciências, atuou por mais de vinte anos no Laboratório de Psicologia Experimental da École de Hautes Études, vinculado à Sorbonne, passando a dirigi-lo em 1912. Em 1921, ele já havia criado o Institut de Psychologie e, em 1923, assumido a cadeira de Fisiologia das Sensações do Collège de France (PAICHELER-HARROUS, 2018). No período que antecede sua vinda ao Brasil, encontrava-se às voltas com as disputas pelo estabelecimento da psicologia como disciplina acadêmica e como ferramenta legítima nos laboratórios franceses.

A trajetória de Roberto Mange, professor responsável pelos cursos de psicotécnica no Liceu de Artes e Ofícios, em 1926, e na Escola de Sociologia e Política, em 1934, é diversa. Graduado em engenharia na Suíça, Mange aceita, em 1913, o convite de Paula Souza, diretor da Escola Politécnica de São Paulo, para integrar seu corpo de professores, tornando-se catedrático de mecânica aplicada. Em 1923, Mange participa da fundação do Liceu, voltado à formação de aprendizes para a indústria, como superintendente, e, no ano seguinte, da inauguração do serviço de seleção e orientação vocacional, onde começa a empregar testes para selecionar candidatos ao curso de mecânica. Ainda em 1923, Mange realiza uma grande viagem à Europa, para conhecer estudos e aplicações da psicotécnica. O serviço de seleção profissional da companhia de bondes alemã o inspiraria a implantar as provas psicotécnicas na seleção de trabalhadores (SENAI, 1991). A chegada de Piéron ao Rio de Janeiro coincide com o momento em que Mange encontrava-se empenhado em ampliar o uso das provas psicotécnicas em São Paulo.

As ideias sobre psicotécnica tecidas por Piéron e Mange em seus cursos forjaram conhecimentos e usos que integraram a formação das primeiras gerações de profissionais às voltas com a psicologia e a psicotécnica no país. Considerando os variados graus nos quais a memorialística tem situado esses autores enquanto formadores do cânon da psicologia brasileira, a análise destes 
cursos fornece uma pista importante das questões em jogo na constituição da psicotécnica e da psicologia como campos disciplinares.

\section{DA PSICOTÉCNICA À PSICOLOGIA: HENRI PIÉRON NA ESCOLA NORMAL}

As anotações do curso de psicotécnica de Piéron na Escola Normal em 1926 foram publicadas como livro impresso em 1927, com o nome de Psychologia e Psychotechnica: publicação do laboratório de Psychologia Experimental. A introdução escrita por Lourenço Filho conta a história do laboratório e o momento no qual as preleções de Piéron se inserem no projeto pedagógico brasileiro. A publicação contém 23 capítulos, divididos em três blocos. $\mathrm{Na}$ primeira parte, estão as aulas sobre psicologia; na segunda, as de psicotécnica; e na terceira, uma descrição das práticas de laboratório.

Ao tecer um apanhado da história da psicologia, Piéron apresenta a disciplina como herdeira da filosofia, o que faria com que trinta anos antes a psicologia não contivesse "nada de prático, apenas conceitos apriorísticos e abstrações" 3 . Agora, ao contrário, na busca de "conhecimentos mais positivos do homem”, a psicologia científica passaria a apoiar-se nas leis extraídas dos experimentos psicofisiológicos inaugurados na Alemanha e a empreender comparações entre as raças 4 , homens e animais, adultos e crianças. Neste contexto, não causava estranheza a enunciação da lei de Fechner sobre a percepção psicológica: "a intervenção do fenômeno da consciência cresce proporcionalmente ao logaritmo da intensidade da excitação" (PIÉRON, 1927, p. 12).

O objetivo da psicologia passava a ser a criação de fórmulas e medidas de

\footnotetext{
3 As citações do texto original foram transcritas, neste artigo, em português contemporâneo.

$4 \mathrm{O}$ texto contém várias afirmações racistas e eurocêntricas, característica comum nos primeiros textos da psicologia diferencial (GOULD, 2014).
} 
funções mentais fisiológicas, capazes de contribuir para o estabelecimento de padrões e possibilitar a comparação e a hierarquização dos indivíduos. Delimitado o escopo da disciplina, os capítulos que se seguem são dedicados à exposição dos "fundamentos sensoriais da psicometria". Nesse contexto, ele dedica-se menos a explorar as origens dos estímulos e explicações para operações da consciência do que a perscrutar leis, matemáticas, da sensação e da percepção. A psicotécnica revelaria "seu valor", assim, em relação às "noções gerais da psicologia” (PIÉRON, 1927, p. 15), que lhe forneceria substrato científico e das quais dependeria por esse motivo.

Piéron dedica boa parte de suas preleções à medida da inteligência, reportando-se às escalas de Binet e de Claparède. Confessando a dificuldade de definir o que a inteligência seja ("... sob o ponto de vista da psicologia teórica, a inteligência não existe. Mas a inteligência é capital quando ela é encarada pelo lado da psicotécnica" (PIÉRON, 1927, p. 67)), apoia-se na assertiva de que "a inteligência não é senão a capacidade de solução de problemas” (PIÉRON, 1927, p. 56). As diferenças desta conceituação em relação àquela de Alfred Binet seriam fruto, segundo Huteau (2006), de divergências conceituais e metodológicas fundantes: enquanto Binet compreendia a inteligência a partir de um paradigma associacionista, calcado em práticas de laboratório, Piéron optaria pela abordagem analítica, decompondo as funções psicológicas em elementos independentes.

Nesse contexto, Piéron defendia que aquilo que não se pode medir, como a consciência ou a afetividade, seria medido pelos seus efeitos. A utilidade da expressão numérica estaria em comparar indivíduos e grupos, avaliar a normalidade e promover a adaptação dos indivíduos. $\mathrm{Na}$ impossibilidade de isolar funções psicológicas, equações matemáticas estariam encarregadas de estabelecer relações entre elas. É desta forma que passam a compor o vocabulário da Psicotécnica os valores significativos ("fim essencial de todo o processo da psicometria”), o centro de gravidade da curva, a média aritmética, a mediana, os quartis, o desvio-padrão, as correlações. 
Que o lugar escolhido para o curso de Piéron em São Paulo fosse a Escola Normal fornece indícios do caráter que se buscava impingir localmente à matéria. Recenseamento conduzido por Sampaio Dória no início da década indicava que cerca de $40 \%$ das crianças em idade escolar encontravam-se fora da escola (SÃO PAULO, 1920; MATHIESON, 2018), revelando um enorme descompasso entre a escolarização da população paulista e o projeto de industrialização em curso. Paralelamente às reformas educacionais, a solução à mão era otimizar o uso da mão-de-obra formada, conduzindo os alunos a postos específicos na indústria, na administração pública e no setor de serviços, tarefas para as quais a psicotécnica mostrava-se promissora.

\section{DA SELEÇÃO AO ENSINO PROFISSIONAL: A PSICOTÉCNICA COMO PROJETO}

Em julho de 1926, Mange publica no jornal O Estado de S. Paulo uma sequência de reportagens descrevendo o uso que vinha sendo feito da psicotécnica no Liceu de Artes e Ofícios (MANGE, 1926, p. 4). O jornal costumava apresentar um resumo de palestras proferidas na cidade na seção "Leituras e Conferências" e a psicotécnica foi tema da coluna em vários momentos. Parte das notas de Piéron também apareceram no jornal, no mês de agosto de 1926 (A ÚLTIMA, 1926, p. 5). O interesse natural que o tema suscita à época é, pois, construído na confluência de acadêmicos envolvidos com o tema, de um público ávido por novidades que visavam "dar maior precisão científica à organização do ensino" (TESTES, 1926, p. 5), e do jornal que pauta o movimento ao longo dos meses de junho, julho e agosto de 1926. O jornal é, portanto, parte do espaço de legitimação dos intelectuais à época, publicando inclusive propagandas de suas produções: 
Mange ressaltava a carência de operários qualificados para a indústria e a necessidade de prevenir acidentes no sistema de transporte5, apresentando a psicotécnica como solução. Nestes textos, ele afirma não apenas que a psicotécnica constituiria um corpo de conhecimentos consolidado na Europa e nos Estados Unidos, uma "ciência moderna", capaz de "descortinar novos horizontes para o aproveitamento das faculdades de trabalho do homem" (MANGE, 1926b, p. 4). O público-alvo do artigo em jornal abarcava o "clamor dos industriais pela falta de operários aptos", mas também os governantes, capazes de financiar a empresa (MANGE, 1926b, p. 4).

O esforço divulgador de Mange renderia frutos. Em 1930, ele participa, com o então diretor da Estrada de Ferro Sorocabana, da inauguração do Serviço de Ensino e Seleção Profissional, onde colocaria em prática projetos de formação envolvendo a psicotécnica. Em 1934, ano em que começa a ministrar o curso de psicotécnica da Escola Livre de Sociologia e Política, Mange é convidado para dirigir o recém-criado Centro Ferroviário de Ensino e Seleção Profissional. Já reconhecido como autoridade em matéria de ensino profissional, Mange torna-se protagonista da fundação do SENAI (Serviço Nacional de Aprendizagem Industrial) em 1942, assumindo a direção do Departamento Regional de São Paulo, cargo que ocuparia até sua morte, em 1955 (SENAI, 1991).

No curso do Liceu de 1926, a seleção profissional de base psicotécnica é defendida como capaz de "(...) colocar cada homem no lugar exato que convém às suas aptidões" (MANGE, 1926a, p.31, grifos nossos). As "provas" fazem do termo "psicotécnica" um adjetivo empregado para qualificar a aplicação de testes, encarregados de "eleger aptidões fundamentais" e estipular "o valor do indivíduo"

\footnotetext{
5 Como revela a quantidade de cartas e dossiês sobre o assunto em seu arquivo pessoal a partir de 1931 (SENAI, 1991, v. 2, p. 44-45).
} 
(MANGE, 1926a, p. 5), destinadas à avaliação de habilidades dos futuros operários para a execução de tarefas manuais. Logo, ultrapassando o mero adjetivo, a psicotécnica é apresentada como "o estudo das faculdades humanas consideradas em vista do seu melhor aproveitamento técnico" (MANGE, 1926a, p. 19), expressando uma visão de ciência articulada a seu caráter aplicado.

Interessante notar o destaque dado por Mange à avaliação das "aptidões" em detrimento da "inteligência", considerado por ele (em concordância com Stern e Spearmann) um conceito de natureza mais ampla e imprecisa (MANGE, 1926a, p. 64). No curso de 1934, quando Mange dedica-se às discussões teóricas que cercam a disciplina, ele trata a própria "inteligência geral" como uma aptidão, em referência a Claparède (MANGE, 1934, 25 a aula, p.1). Contrastando com as formulações de Piéron, destaca a pouca serventia de um coeficiente geral de inteligência, em favor da necessidade de isolar funções psicológicas para a avaliação específica delas.

Segundo Turbiaux (2017), no início do século XX, as discussões na área, com o envolvimento de nomes de peso da psicotécnica europeia, como Lahy, Remy, Claparède e Franziska Baumgarten, vinham sendo deslocadas para o conceito de aptidão profissional. A menção a muitos desses autores nos cursos de Mange fornece indício tanto do quão atualizado o suíço estava em relação a esses debates, bem como do modo como ele se posiciona em relação às disputas em voga. 
Figura 2 - Participantes do curso que Henri Piéron proferiu na Escola Normal de São Paulo, cujas notas deram origem ao livreto "Psicologia e Psicotécnica" publicado em 1927. Da Esquerda para a Direita em pé: 6- Manuel Bergström Lourenço Filho; Sentados: 1- Noemi Marques da

Silveira (Rudolfer); 3- Roberto Mange; 4- Senhora Piéron; 5- Henri Piéron.

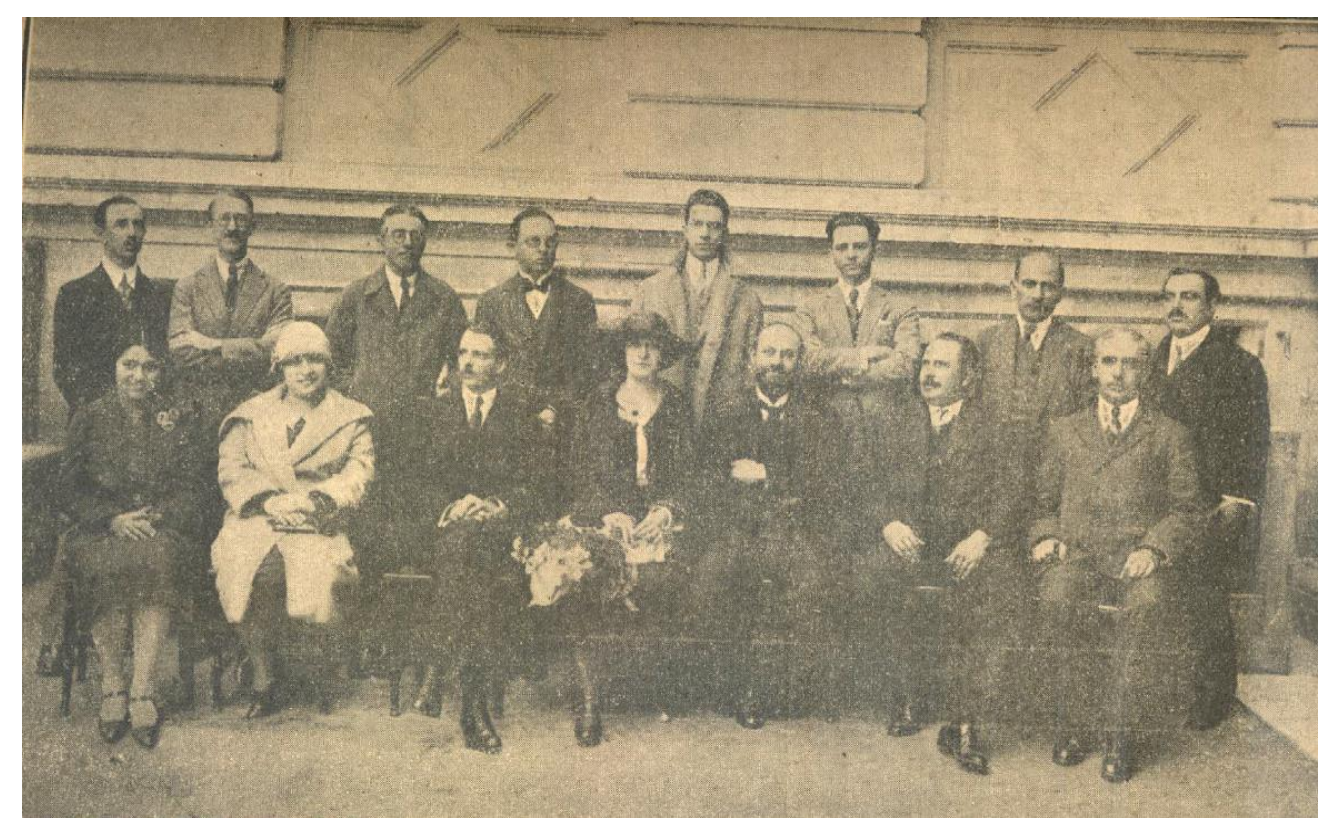

Fonte: (Piéron, 1927).

Ao dividir, tanto no curso de 1926 quanto no curso de 1934, as provas psicotécnicas em "sintéticas" e "analíticas" (para investigação de funções psicomotoras específicas), Mange segue a formulação teórica de Piéron. Mange acompanhou o curso do especialista francês, como mostra a foto que consta na contracapa da edição do curso de Piéron (Figura 2). Na verdade, Mange acompanhava os trabalhos de Piéron há algum tempo. Melo encontrou cartas de Mange a Piéron que tratariam inclusive de "uma parceria entre o SENAI e o Instituto Nacional de Orientação Profissional (INOP)” (MELO, 2016, p. 177). Neste primeiro momento e sob impulso do taylorismo em voga, o desenvolvimento da disciplina encontrava, em ambos, rumos confluentes: caracterizar a psicotécnica como ciência da adaptação do homem à tarefa.

Passados oito anos de seu oferecimento no Liceu, em 1934, a disciplina "Psicotécnica" faz seu ingresso na academia pelas mãos de Mange. Anuários da Escola Livre de Sociologia e Política mostram que o curso de Mange é bem- 
sucedido, e perdura até 1944. O programa do curso de $1940^{6}$, que contém também algumas indicações bibliográficas, auxilia em nossa leitura do curso de 1934 (e vice-versa), e a observar melhor algumas diferenças deste em relação ao curso de 1926.

As anotações do curso de 1934 - a sebenta - foram datilografadas por um aluno desconhecido, encadernadas e dadas de presente a Mange 7 . O curso, semestral, iniciado em 19 de fevereiro e concluído em 28 de maio de 1934, foi dividido em 27 aulas, ministradas duas vezes por semana. Enquanto o curso de 1926 enfatizava a aplicação de provas psicotécnicas, o curso de 1934 expõe sua inserção nas áreas industrial e do trabalho e inclui uma narrativa sobre o desenvolvimento histórico da matéria. Já na terceira aula, percebemos um deslocamento da antiga preocupação em defender a seleção profissional como campo de atuação da psicotécnica, na direção da formação profissional - o que será importante para fundamentar o campo que Mange busca instaurar na educação para o trabalho.

\section{COMPARANDO VERSÕES: PSICOTÉCNICA, TECNO- PSICOLOGIA E ERGONOMIA}

Para explicar como a psicologia se insere na área do trabalho, Mange vale-se dos conhecimentos da tecno-psicologia. A lista de "livros recomendados" da ementa de 1940 elucida a origem do termo: o livro Tecno-psicologia do trabalho industrial, de Walther, aparece em todas as ementas de curso de Mange nos Anuários. Notícias em periódicos da época mostram que León Walther, professor russo da Universidade de Genebra, estivera no Brasil em 1929,

\footnotetext{
${ }^{6}$ As ementas registradas entre os anos de 1940 e 1943 são idênticas, por isso tomamos, para comparação com cursos anteriores, a ementa de 1940. Em 1944, a ementa sofre algumas modificações, quando passa a ser dividida com a profa. Maria de Lourdes Campos Viégas.

7 Zanetti (2001) analisou as seis primeiras aulas disponíveis no dossiê Roberto Mange, do Arquivo Edgard Leurenroth, na UNICAMP. A análise que aqui fizemos engloba o texto completo, com as 27 aulas, que encontramos na biblioteca da Faculdade de Direito da Universidade de São Paulo.
} 
ministrando uma conferência na Associação Comercial de São Paulo (A SELECÇÃO 1929, p. 6). Ainda que não saibamos se Mange esteve envolvido com a vinda de Walther ao país, percebemos na leitura da sebenta de 1934 uma aproximação à obra do russo.

Os tópicos de conteúdo são os mesmos na introdução dos cursos de 1934 e de 1940, mas há uma diferença na ordem de exposição, sugerindo uma mudança na linha de raciocínio que conduz Mange às conclusões finais. No curso de 1934, "Aptidões Profissionais" ocupa a parte mais extensa do curso, e também o encerra. Seguindo Münsterberg, Mange observa que a "psicotécnica é a ciência da aplicação prática da psicologia aos problemas culturais" (MANGE, 1934, $1^{\text {a }}$. aula, p. 1) - entendendo-se por cultural, aqui, os problemas gerados pelas atividades humanas com um fim prático (leia-se técnico, como o era para Piéron).

A inserção da tecno-psicologia no curso de 1934 implica em uma mudança relevante na caracterização da psicotécnica. Definição constante na 4a. aula da sebenta, "Tecno-Psicologia é a adaptação dos elementos do trabalho ao indivíduo" (MANGE, 1934, 4ª aula, p.2, grifos nossos), em sentido contrário ao proposto anteriormente, quando o propósito era o de adaptar o indivíduo ao trabalho. Ainda que os dois objetivos de adaptação homem-trabalho não pareçam incompatíveis, há uma mudança de enfoque quando se destaca a necessidade de adaptar o indivíduo ao trabalho ou o trabalho ao indivíduo e, consequentemente, de estratégias para sua consecução.

A posição de Mange acompanha um debate corrente à época acerca da finalidade dos testes tanto no Brasil quanto no exterior. Nos Estados Unidos, Gould (2014) descreve uma série de críticas que as práticas de testagem receberam no que se refere tanto às dificuldades na sua aplicação quanto aos seus usos nos planos de ação social e de prática educativa. Em relação a esta última questão, os hereditaristas viam nos diagnósticos dos testes "limitações permanentes", prescrevendo então "um tipo de instrução adequada à sua herança e uma formação profissional adequada às suas possibilidades biológicas", ao passo que os culturalistas consideravam a testagem parte de uma "teoria do 
incremento das potencialidades através de uma educação adequada" (GOULD, 2014, p. 156).

No caso brasileiro, também houve problemas na aplicação dos testes (JACÓ-VILELA, 2014, p. 9). Em relação aos seus usos nas políticas educacionais, a psicotécnica terá papel fundamental na organização escolar, inclusive entre os autores do Manifesto dos Pioneiros da Educação Nova, em 1932. Gualtieri defende, no entanto, que os escolanovistas mudaram de opinião no período. Fernando Azevedo, em torno de 1930, migrou de uma educação transformista, "em que exercícios físicos alterariam características indesejáveis dos indivíduos e, consequentemente, da "raça", para uma "perspectiva selecionista que promove os considerados mais capazes". Em uma segunda fase, que conformou o Manifesto de 1932, Azevedo teria passado a vislumbrar uma "escola acessível a todos os cidadãos do país, mesmo em condições de inferioridade econômica, para obter deles o máximo de desenvolvimento conforme suas 'aptidões vitais"” (GUALTIERI, 2018, p. 494). Ou seja, assim como a indústria, a escola também precisaria conformar-se ao seu público.

Passados seis anos desde o primeiro curso ministrado por Mange, e quatorze em relação ao curso inaugural do Liceu, a psicotécnica de Mange consolidara-se na área do trabalho, encontrando tanto aplicação quanto justificativa. Tornando prescindível a preocupação - central no curso de 1934 com a defesa da formação profissional, fazendo supor que os profissionais especializados em psicotécnica já seriam, no virar da década, absorvidos não mais apenas por escolas do SENAI, Liceu e outras, mas diretamente pela indústria. No anuário do sétimo semestre letivo de 1940, o curso de psicotécnica figura com a seguinte apresentação:

Esta cadeira elucida fatores de adaptação do homem ao trabalho e os de ajustamento de trabalho ao obreiro. São estudados os métodos de determinação das aptidões necessárias à execução do trabalho, os meios de pesquisá-las para fins de seleção profissional, os processos de aquisição da técnica do trabalho e a forma de adaptar os elementos de trabalho e o ambiente à constituição física e psíquica do trabalhador. 
Esses estudos visam maior eficiência do fator humano no trabalho a par de menor gasto energético (ELSP, 1940, p.42).

Breve comparação desta ementa com as notas de cursos anteriores mostra que Mange havia incorporado os preceitos da tecno-psicologia, e que os diálogos com a ergologia, iniciados no curso de 1934, tornaram-se mais intensos. O tópico "Aptidões Profissionais" encolhe, e passa para o meio do curso, que agora se encerra tratando da "Organização Tecno-Psicológica do Trabalho" (não mais "organização racional do trabalho" (ORT), que passa para o início do curso, ilustrando o desenvolvimento histórico da disciplina) e da "Missão social da psicotécnica nas atividades produtoras do país".

Quadro 1 - Perfil das citações das obras de Mange (à esquerda) e Piéron (à direita). O tamanho das letras é proporcional ao número de citações. Em vermelho, os autores que compõe o corpus comum aos dois autores.

\begin{tabular}{|c|c|}
\hline OBRAS DE MANGE & OBRA DE PIÉRON \\
\hline $\begin{array}{l}\text { Atwter, Atzler, Baumgarten, Binet, } \\
\text { Blumenfeld, Carrard, Charles Henry, } \\
\text { Christiaens, Claparède, Collin, } \\
\text { Fechner, Friedrich, Galton, } \\
\text { Gauss, Gemelli, Giese, Gilbreth, } \\
\text { Heiland Moede, Imbert, Isaias } \\
\text { Alves, Jules Amar, Klutke, Kobis, } \\
\text { Kraepelin, Kunze, Lahy, Lipmann, Marbe, } \\
\text { Marrey, Mauvesin, Mira, Mosso, } \\
\text { Müinsterberg, Nepper, Parsons, Pascal, } \\
\text { Piéron, Piorkowski, Pizzoli, Poppelreuter, Ries, } \\
\text { Rorschach, Rossolim, Ruffer, Rupp, Rybakow, } \\
\text { Schulz, Stern, Stilling, Strong, Strumelin, } \\
\text { Taylor, Tetens, Toulouse, Tramm, Weber, } \\
\text { Whipple }\end{array}$ & $\begin{array}{l}\text { Arago, Arquimedes, Arsonval, Bal Frederic, } \\
\text { Bergson, Binet, Blondel, Bouguet, Bravais, } \\
\text { Camion, Charles Henry, Claparède, } \\
\text { Comte, Condillac, Condorcet, De Sanctis, } \\
\text { Decroly, Diaget, Dumas, Ebbinghans, } \\
\text { Eulemberg, Fechner, Ferrar, } \\
\text { Foucault, Freud, Galton, Gemell, } \\
\text { Guicciardi, Haberlandt, Helvetius, Kraepelin, } \\
\text { Kraig, Lahy, Lange, Langier, Lapicque, Levy } \\
\text { Bruhl, Lipmann, Loeb, Mac Cattell, Mayorsky, } \\
\text { Mosso, Münsterberg, Noel, Ostwald, Patrizzi, } \\
\text { Pawlow, Pearson, Piéron, Pizzoli, } \\
\text { Ribot, Simon, Snellen, Sócrates, } \\
\text { Spearmann, Stern, Sulzer, Tebakoff, } \\
\text { Toulouse, Vaschide, Vermeylen, } \\
\text { Victor Henri, Von Frey, Watson, } \\
\text { Weber, Whipple, William } \\
\text { James, Wundt }\end{array}$ \\
\hline
\end{tabular}

Fonte: elaboração própria a partir das obras. 
Analisando a menção a outros autores na sebenta de 1934 (Quadro 1), encontramos referências a um conjunto de nomes francamente contrapostos à ORT, como o do alemão Otto Lipmann e do francês Jules Amar. Amar é considerado na França um dos precursores da ergonomia. Pesquisador atuante no início do século XX, publicou, em 1914, O motor humano - propondo um estudo científico de dados físicos e fisiológicos relacionados à eficiência no trabalho -, além de dirigir o laboratório de investigações do trabalho industrial no Conservatoire National des Arts et Métiers de Paris. Amar defendia que fatores ambientais como luz, temperatura e ruídos influenciavam no desempenho humano. Segundo Alves et al (2010), Amar empenhou-se em verificar experimentalmente os princípios de Taylor, acusados à época de falta de embasamento, valendo-se, dentre outros aparelhos, da cronofotografia, que capturava as diversas fases do movimento em uma única foto, permitindo analisar a progressão do movimento.

O trabalho de Taylor não tinha sido bem recebido pelos trabalhadores na França. As reações contra os preceitos da ORT paralisaram fábricas como a Renault, e Amar esteve entre os apoiadores do movimento. Para Reuchlin (1971), nomes da psicotécnica como Jean-Maurice Lahy já seriam anti-tayloristas ao defender que os problemas do trabalho precisavam ser considerados em respeito às características e qualidades de cada trabalhador. Ouvrier-Bonnaz (2006, p. 60) vai ainda mais longe, sustentando que a própria psicotécnica teria surgido como resposta crítica ao taylorismo.

Segundo Bertolli Filho (2003), industrialistas brasileiros teriam patrocinado a vinda de nomes da psicotécnica mundial ao Brasil por acreditarem que havia uma convergência entre os objetivos da psicotécnica e do taylorismo, e Mange valeu-se deste entusiasmo para abrir caminhos para a psicotécnica. No entanto, as empresas acabaram por mostrar-se pouco dispostas a "arcar com os custos representados pela multiplicidade e pela abrangência das orientações prescritas pelos "psicólogos" (BERTOLLI FILHO, 1993, p. 43), a despeito da maior preocupação com as doenças e acidentes do trabalho entre empresários e 
governo brasileiros nas décadas de 1920 e 1930 (ALMEIDA, 2015). Possibilidade mais concreta de inserção social para a psicotécnica abriu-se, como vimos, na área educacional - o que leva Mange a dirigir seus esforços em psicotécnica para a educação de trabalhadores.

Zanetti (2005) sustenta que a guinada educacional empreendida por Mange seria em si anti-taylorista, pois Taylor em nenhuma passagem de seus escritos manifestou intenção de formar mão-de-obra. Os projetos de Taylor envolviam a expropriação dos saberes operários, ao passo que as propostas de Mange oscilavam entre a substituição/alocação de trabalhadores (via seleção profissional) e a elevação do nível técnico do operariado.

Em 1940, Mange propõe uma linha histórica de desenvolvimento da psicotécnica, partindo de sua relação com a ORT, passando pela seleção e formação profissional, na direção da "adaptação psicotécnica dos elementos do trabalho ao homem" - ora vista como aquilo que de mais avançado a psicotécnica fora capaz de produzir. A quarta parte do curso irá explorar elementos da adaptação do trabalho ao indivíduo e da racionalização do lugar de trabalho.

Assim, é possível estabelecer uma periodização das contribuições de Mange à psicotécnica em três fases: 1) até 1926, Mange vale-se da difusão do taylorismo nos meios industriais brasileiros para lançar as bases da psicotécnica. 2) de 1926 a 1934, a psicotécnica de Mange distancia-se da mera testagem para voltar-se ao treinamento profissional, articulando-se com anti-tayloristas franceses e alemães; 3) de 1934 a 1940, Mange aproxima-se da ergologia, inaugurando uma inserção mais social (ou industrial, como queria Cabral) da matéria.

Ao considerar a obra de Mange de forma dinâmica, podemos problematizar (DOMINSCHEK, 2011; SATO, 2003, p.42) a associação causal entre psicotécnica e taylorismo, colocando o nome de Mange ao mesmo tempo como precursor e impulsionador das ideias de Taylor no Brasil.

Em 1944, a ementa do curso de psicotécnica sofre nova transformação. 
Agora, duas partes da disciplina serão dedicadas a questões ergonômicas: a sexta, relacionando as condições de trabalho à eficiência do trabalhador; e a sétima (e última), tratando das condições do ambiente de trabalho. A bibliografia recomendada, mais extensa que antes, passa a incluir diversos títulos de psicologia do trabalho, orientação e aconselhamento profissional - constituindo as bases para a segmentação interna da psicologia que começava a se estabelecer.

Se, à primeira vista, por serem engenheiro e médico, ou, por engajaremse com o trabalho industrial e a escola, Mange e Piéron parecem defender projetos distintos, nossa análise mostrou, ao contrário, uma convergência teórica e prática dos dois em muitos pontos. Piéron tem sua biografia ligada à fundação do Institut National D'Orientation Professionnelle (INOP), responsável pela orientação escolar e profissional na França (MARTIN, 2017), e Mange aos cursos de formação de ferroviários, do IDORT e do SENAI.

Um projeto global, deslocalizado de disciplina, reproduz-se, portanto, graças aos seus pressupostos de análise: a testagem não leva em conta as particularidades culturais do testado; a inteligência e as habilidades psicológicas são pensadas como características biológicas, desigualmente distribuídas pelo planeta; as ferramentas estatísticas e matemáticas são capazes de medir e reproduzir os resultados alhures, possibilitando a circulação de intelectuais, textos e de equipamentos mundo afora. A coexistência de um conjunto de autores de referência nos textos de Mange e Piéron (Quadro 1), como Binet, Claparède, Fechner, Galton. Resta-nos saber como as contribuições de Piéron e Mange são aclimatadas e percebidas pelos praticantes da psicologia nos anos subsequentes.

\section{MANGE \& PIÉRON: EFEITOS HISTORIOGRÁFICOS}

Em pioneiro balanço da área, nos anos 1950, Annita de Castilho Marcondes Cabral, professora da cadeira de psicologia da Faculdade de Filosofia, Ciências e Letras da Universidade de São Paulo, afirma: 
A segunda metade deste meio século vê irromper o movimento a favor dos testes, tipicamente norte-americano. Inicia-o Medeiros e Albuquerque com uma conferência no Rio de Janeiro, seguida de um excelente livro: Tests. Na Baía, Isaías Alves imediatamente encomenda nos Estados Unidos e na Inglaterra as obras recomendadas por Medeiros, e alguns anos mais tarde vai conhecer diretamente nas fontes a nova Psicologia norte-americana, no famoso Teachers College, da Universidade de Columbia. Pouco antes, Lourenço Filho descobrira em S. Paulo a pequena biblioteca pedagógica de uma instituição americana e também começara a trabalhar com testes. Pouco após a primeira conferência de Medeiros, vem dar cursos no Brasil o psicólogo $\mathrm{H}$. Piéron e sua influência favorável às medidas objetivas empresta o tradicional prestígio francês ao movimento iniciado. O livro de Claparède sobre o mesmo assunto vem trazer a um público ainda não tão afeito à língua inglesa as bases técnicas e um variado repertório de provas de inteligência e de aptidão (CABRAL, 1950, p. 34, grifo nosso) ${ }^{8}$.

Escrevendo a um público estadunidense, Cabral preocupa-se em defender o protagonismo da influência americana no desenvolvimento da disciplina no Brasil, mas também em conferir uma certa unidade ao "movimento dos testes" que, embora americano em origem, seria associado no Brasil a acadêmicos franceses, por conta de seu "prestígio" e afinidade linguística.

De forma diversa, Lourenço Filho, em relato de 1956, busca caracterizar a psicotécnica como uma confluência de interesses de médicos, educadores, engenheiros e padres, brasileiros e estrangeiros. Sobre Henri Piéron, ele dirá:

Como suas lições e demonstrações já encontrassem em plena atividade núcleos de aplicação à educação e à organização do trabalho, foram elas avidamente seguidas. Piéron teve oportunidade de oferecer não só princípios e técnicas de psicologia aplicada, como a discussão de problemas metodológicos, o que muito influiu na direção dos estudos de seus discípulos de então, entre os quais Roberto Mange, Lourenço Filho e Noemi Rudolfer (LOURENÇO FILHO, 1955, p. 283).

\footnotetext{
8 O texto original em inglês, segundo nota da autora, foi escrito como capítulo (Psychology in Brazil) do livro World Psychology, que estaria então no prelo para ser publicado nos Estados Unidos pela Universidade de Cincinnati. Annita Cabral esteve mais de uma vez naquele país para realizar estudos na década de 1940.
} 
De uma perspectiva historiográfica, é preciso notar que a questão estava marcada pelas políticas culturais estadunidense e francesa em relação ao Brasil e à América do Sul, embaralhando as produções da época. Entre os levantamentos bibliográficos e dos praticantes da psicologia, na época, similares ao de Lourenço Filho e de Annita Cabral, encontra-se "Psychology in South America", escrito em 1941 pelos professores de Harvard J.G. Beebe-Center e Ross A. McFarland, e "The present status of psychology in South America", escrito por Margaret Hall (CAMPOS et al, 2010). São produções, no entanto, com fatura muito distinta. Os textos de Cabral, Beebe-Center e McFarland, e Hall são produzidos em resposta às políticas de aproximação dos Estados Unidos com a América Latina e ao desenvolvimento dos estudos de área americanos (HANKE 1947). Assim, eles devem ser lidos como uma cartografia de quem faz e o que faz, na América Latina e no Brasil, para aqueles que porventura venham se aventurar em assuntos latinoamericanos. Ao passo que o texto de Lourenço Filho deve ser pensado dentro dos esforços de autocelebração dos fundadores das universidades, vinte anos após a sua criação.

Importante notar a maneira como as disputas entre escolas e influências vão conformando as representações sobre a psicologia no Brasil. A necessidade percebida por Cabral de minimizar a participação francesa na história local da psicologia parece compor uma narrativa voltada à consolidação de uma disciplina dotada não apenas de métodos específicos, mas devedora dos textos e autores americanos: "Na segunda década deste século começou a influência norteamericana a se fazer sentir, mas ainda, assim, via-França" (CABRAL, 1950, p.34). É exemplar dessas disputas o modo como são construídas as filiações intelectuais de Noemi Rudolfer. Embora ela tenha feito uma série de estudos nos Estados Unidos (MORAES, 2012), o que confirmaria a tese geral da influência americana de Annita Cabral, é tida como discípula de Henri Piéron por Lourenço Filho.

Segundo Castro, Facchinetti e Portugal (2018), Lourenço Filho apresenta a psicotécnica como "prática unificada para áreas convergentes e similares" (CASTRO et al, 2018, p.8), mesmo percebendo a existência de assimetrias entre 
seus campos de aplicação. Em artigo, Lourenço Filho apresenta uma longa lista de "especialistas estrangeiros" que passaram pelo país que, segundo ele, contribuíram para a conformação do campo. Cabral, por sua vez, separa os que "são treinados empiricamente" dos que problematizam a pesquisa, discutem "o método de chegar às afirmações" (CABRAL, 1950, p. 33), caracterizando os trabalhos de Mange e seus discípulos como "psicologia industrial", "orientada para fins práticos, não de pesquisa” (CABRAL, 1950, p. 33).

Soluções díspares de Annita Cabral e Lourenço Filho, portanto, ao sabor das forças do campo ${ }^{9} \mathrm{em}$ franca reorganização desde a passagem do americano Otto Klineberg pela FFCL-USP, de 1945 a 1947, e à onda de profissionalização marcada pela criação da Associação Brasileira de Psicotécnica (ABP), em 1949, capitaneada por Mira y López, que culminará com o primeiro pré-projeto de regulamentação da profissão de psicologista encabeçado pela ABP em 1953 (O Problema, 1954).

Após considerarmos o modo como as políticas culturais estrangeiras e os interesses locais interferiram nas representações sobre o campo da psicologia na época, e, lermos os trabalhos de Mange e Piéron, aqui analisados, somos levados a reenquadrar o problema da relevância da identidade nacional na configuração na área. No meio dessa lista de autores (Quadro 1), veremos também americanos, alemães e ingleses, que de uma perspectiva de formação não podem ser considerados "nacionais". Nos Estados Unidos, o projeto de psicotécnica nascia da apropriação de Binet pelos americanos (GOULD, 2014, p. 158), muitos dos quais orientados, por sua vez, por professores alemães, ora na Alemanha por Wundt, ora em Harvard, por Münsterberg (PAICHELER-HARROUS, 2018; GOMES 2004). Assim, Wundt e Binet chegam ao Brasil por meio de várias mediações, amalgamados a outros textos.

Não se trata, portanto, de defender a filiação da psicologia brasileira aos americanos ou franceses, como quis a memorialística. A discussão da filiação

${ }^{9}$ No sentido proposto por Pierre Bourdieu (2003). 
estrangeira somente encontra um contexto se considerarmos as apropriações que as elites locais farão das políticas culturais para a América Latina e para o Brasil, gestadas por organismos europeus e americanos. Durante o século XIX, é a França que detém a hegemonia das trocas culturais estrangeiras no Brasil, ao passo que nas primeiras décadas do século XX outros países vão abrindo frentes, de maneira que nos anos 30, a fundação das universidades se dará a partir da entrada de outros atores internacionais, como a Itália (SILVA \& SIQUEIRA, 2018), a Alemanha (CÂNDIDO DA SILVA, 2013) e os Estados Unidos (MARINHO, 2001; FREIRE JUNIOR\& SILVA, 2014).

Annita Cabral e Lourenço Filho irão angariar e defender, cada qual, os capitais simbólicos advindos da associação de seus trabalhos e de seus nomes às traduções de obras de professores estrangeiros, na perfilação desses professores nas seções de cultura dos jornais locais, no oferecimento de personalidades internacionais à história local das disciplinas. Tais intelectuais constroem nesses encontros interessados um capital internacional, financiado pelo jogo geopolítico do período. Capitais fundamentais na organização do campo, no começo dos anos 50 no Brasil.

\section{CONSIDERAÇÕES FINAIS}

A apresentação da psicologia como disciplina científica causa-nos hoje a impressão de que áreas como a psicotécnica constituíam um ramo do tronco "psi". Ao investigar a história da área, contudo, descobrimos que ambas se encontravam imbricadas no início da constituição do campo no Brasil. Mais do que isso, a psicotécnica consolida-se institucionalmente de forma mais consistente entre 1920 e 1930, fazendo com que a psicologia brasileira crescesse a seu reboque. Atestam essa hipótese, no caso brasileiro, a ocorrência simultânea da psicologia e da psicotécnica no curso proposto por Piéron, a livre circulação de intelectuais entre essas áreas e ter como primeiro órgão de classe uma instituição indistinta, a Associação Brasileira de Psicotécnica. 
Inicialmente, concordamos que o emprego da psicotécnica por Mange no ensino industrial confere expressão para o que Antunes (2012) e Moraes (2000) consideram parte de um movimento de racionalização da prática educativa, coincidente menos com um ideal de desenvolvimento do indivíduo, e mais com aquele da integração indivíduo-trabalho. O sentido dessa integração, no entanto, vai se transformando com a evolução do curso de psicotécnica de Mange, ecoando leituras da obra de autores como León Walther e Jules Amar. O que não passa despercebido a Annita Cabral, ao classificar o trabalho do engenheiro como "psicologia industrial", não mais como psicotécnica (CABRAL, 1950, p. 40). A análise aqui desenvolvida questiona o modo como Roberto Mange vem sendo considerado no jogo de contradições que compõe a história das ideias na psicologia brasileira - processo por vezes negado ou relegado a segundo plano na construção de narrativas mais ou menos críticas ou edificantes da área.

A pretensa unidade da psicotécnica, ou mesmo da psicologia brasileira, sugerida por Annita Cabral, não se confirma. "Práticas supostamente convergentes”, por sua vez, segundo a narrativa de Lourenço Filho, podem ser confirmadas desde que o escopo da psicotécnica é ampliado ao se perscrutar mercados e formas de aplicação para a disciplina nascente. Por outro lado, a fortuna de Piéron na história da psicologia brasileira, em detrimento daquela de Mange, parece relacionar-se mais com a disputa, já anunciada pelo texto de Cabral, entre modelos de universidade diversos, defendidos como mais ou menos próximos daquele americano, do que pelo papel efetivo de cada um deles na construção da área.

Evidencia-se, assim, o modo como as áreas vão sendo reconstruídas, em movimento permanente, influenciadas pela circulação material de obras e personagens, recepção de suas ideias e interesses em pauta - inclusive aqueles geopolíticos e locais, e suas combinações, contribuindo decisivamente para a singular conformação das instituições profissionais e acadêmicas do país. 


\section{REFERÊNCIAS}

ALMEIDA, Anna Beatriz de Sá. As doenças ‘do trabalho’ no Brasil no contexto das políticas públicas voltadas ao trabalhador (1920-1950). Revista Mundos do Trabalho, v.7, n.13, p.65-84, 2015. DOI: http://dx.doi.org/10.5007/19849222.2014V7n13p65

ALVES, Silvana Aparecida; QUEIROZ, Frederico Reinaldo Corrêa; SILVA, José Carlos Plácido; PASCHOARELLI, Luis Carlos. A arte do trabalho: Jules Amar. In: SILVA, José Carlos Plácido e PASCHOARELLI, Luis Carlos (Org). A evolução histórica da ergonomia no mundo e seus pioneiros [online]. São Paulo: UNESP / Cultura Acadêmica, 2010.

ANTUNES, Mitsuko Aparecida Makino. A Psicologia no Brasil: um ensaio sobre suas contradições. Psicologia Ciência \& Profissão, n.32, p.44-65, 2012.

ANTUNES, Mitsuko Aparecida Makino. A psicologia no Brasil: leitura histórica sobre sua constituição. 5. ed. São Paulo: EDUC, 2014.

ANTUNES, Mitsuko Aparecida Makino. Sobre a obra de Manoel Bomfim: Um estudo sobre "Lições de pedagogia: theoria e pratica da educação". PSICOLOGIA ESCOLAR E EDUCACIONAL, v. 20, p. 397-402, 2016.

A QUESTÃO dos menores nas fábricas: como o juiz Mello Mattos mantem o seu despacho. CORREIO DA MANHÃ, São Paulo, 7 de abril de 1929, p. 7.

A SELECÇÃO profissional em face da Psychotechnica: a conferencia que o professor Leon Walther realisou hontem na séde da Associação Commercial de S.Paulo. O ESTADO DE SÃO PAULO, São Paulo, 16 ago. 1929, p.6.

A ÚLTIMA conferência do professor Piéron - Calculos de correlação em psychotechnica. O ESTADO DE SÃO PAULO, São Paulo, 20 ago. 1926. Coluna "Leituras e Conferências", p. 5.

BERTOLLI FILHO, Cláudio. Medicina e Trabalho: as "ciências do comportamento" na década de 40. Revista de História, n. 127/128, p.37-51, 1993. DOI: https://doi.org/10.116o6/issn.2316-9141.voi127-128p37-51

BOURDIEU, Pierre. O campo científico. In: ORTIZ, Renato. (Org.). A sociologia de Pierre Bourdieu. São Paulo: Olho D’água, 2003, p.112-143.

CABRAL, Annita de Castilho e Marcondes. A psicologia no Brasil. Psicologia, n.3. Boletim da Faculdade de Fílosofia, Ciências e Letras, Universidade de São Paulo, v. CXIX, p. 9-52, 1950. 
CAMPOS, Regina Helena de Freitas; LOURENÇO, Érica; ANTONINI, Isabel Gontijo. Helena Antipoff e a psicologia no Brasil. In: CAMPOS, Regina Helena de Freitas (Org.). Helena Antipoff: Textos escolhidos. São Paulo: Casa do Psicólogo; Brasília: Conselho Federal de Psicologia, 2002, p. 13-31.

CAMPOS, Regina Helena de Freitas; JACÓ-VILELA, Ana Maria; MASSIMI, Marina. Historiography of psychology in Brazil: pioneer works, recent developments. History of Psychology, v. 13, n. 3, p. 250-276, 2010.

CÂNDIDO DA SILVA, André Felipe. A diplomacia das cátedras: a política cultural externa alemã e o ensino superior paulista - os casos da USP e da Escola Paulista de Medicina (1934-1942). História (São Paulo), v.32, n.1, p. 401431, jan./jun. 2013.

CASTRO, Alexandre de Castro; FACCHINETTI, Cristiana; PORTUGAL, Francisco Teixeira. Técnicas, saberes e práticas psicológicas na Primeira República (1889-1930). Psicologia em Estudo, n.23, p.3-12, 2018. DOI: 10.4025/psicolestud. v23.37446

CHARTIER, Roger. O mundo como representação. Estudos Avançados, v.11, n.5, p.173-191, 1991.

DOMINSCHEK, Desirê Luciane. A concepção de ensino pensada por Roberto Mange - a formação de mão-de-obra SENAI: a escola do SENAI-PR. História \& Ensino, Londrina, v.17, n.1, p.195-210, 2011. DOI:

http://dx.doi.org/10.5433/2238-3018.2011v17n1p195

ELSP - ESCOLA LIVRE DE SOCIOLOGIA E POLÍTICA. Psicotécnica. Seção "Programas". Anuário da Escola Livre de Sociologia e Política de São Paulo (Instituição Complementar da Universidade de São Paulo). Sétimo Ano Letivo. São Paulo: ELSP, 1940, p.42-3.

ELSP - ESCOLA LIVRE DE SOCIOLOGIA E POLÍTICA. Psicotécnica. Seção "Programas". Anuário da Escola Livre de Sociologia e Política de São Paulo (Instituição Complementar da Universidade de São Paulo). Nono Ano Letivo. São Paulo: ELSP, 1942, p.46-47.

ELSP - ESCOLA LIVRE DE SOCIOLOGIA E POLÍTICA. Psicotécnica. Seção "Programas". Anuário da Escola Livre de Sociologia e Política de São Paulo (Instituição Complementar da Universidade de São Paulo). Décimo Ano Letivo. São Paulo: ELSP, 1943, p.41-42.

ELSP - ESCOLA LIVRE DE SOCIOLOGIA E POLÍTICA. Psicotécnica. Seção "Programas". Anuário da Escola Livre de Sociologia e Política de São Paulo 
(Instituição Complementar da Universidade de São Paulo). Décimo Primeiro Ano Letivo. São Paulo: ELSP, 1944, p.46-47.

FREIRE JUNIOR, Olival; SILVA, Indianara. Diplomacia e ciência no contexto da Segunda Guerra Mundial: a viagem de Arthur Compton ao Brasil em 1941. Revista Brasileira de História, São Paulo, v. 34, n. 67, p. 181-201, 2014. https://doi.org/10.1590/S0102-01882014000100009

GOMES, William. Avaliação Psicológica no Brasil: Tests de Medeiros e Albuquerque Psychological Evaluation in Brazil: Tests by Medeiros-eAlbuquerque. Avaliação Psicologica, v.3, n.1, p. 59-58, 2004.

GOULD, Stephen Jay. A falsa medida do homem. Tradução Válier Lellis Siqueira. São Paulo: WMF Martins Fontes, 2014.

GUALTIERI, Regina. Da regeneração social ao direito biológico: um ponto de inflexão nas propostas educacionais de Fernando de Azevedo. Revista Eletrônica de Educação, v. 12, n.2, p. 483-500, 2018. http://dx.doi.org./10.14244/198271992094

HANKE, Louis. The Development of Latin-American Studies in the United States, 1939-1945. The Americas, v. 4, n. 1, p. 32-64, jul. 1947.

HUTEAU, Michel. Alfred Binet et la psychologie de l'intelligence. Le Journal des psychologues, v.1, n.234, p. 24-28, 2006. DOI: 10.3917/jdp.234.0024. Disponível em:https://www.cairn.info/revue-le-journal-des-psychologues2006-1-page-24.htm . Acesso em: 08 abr. 2020.

JACÓ-VILELA, Ana Maria. Psychological measurement in Brazil in the 1920 s and 1930s. History of Psychology, v. 17, n.3, p. 237-248, 2014.

JACÓ-VILELA, Ana Maria; RODRIGUES, Igor. Emilio Mira y López: Uma ciência para além da academia. Arquivos Brasileiros de Psicologia, v. 66, n. 3 , p. 148-159, 2014.

LIVROS novos. O ESTADO DE SÃO PAULO, São Paulo, 02 jan. 1927, p. 2.

LOURENÇO FILHO, Manuel Bergström. A psicologia no Brasil. In: AZEVEDO, F. de. (Org.). As ciências no Brasil. São Paulo: Melhoramentos, 1955, p.263296.

MANGE, Roberto. A evolução da Psicotécnica em São Paulo. Arquivos Brasileiros de Psicotécnica, v.8, n.1, p. 5-7, 1956.

MANGE, Roberto. Psychotechnica: as provas psychotechnicas nas estradas de 
ferro. O Estado de S. Paulo, o8 de jul. 1926, p.4.

MANGE, Roberto. Psychotechnica. Sebenta-Apostila de Aula. Biblioteca da Faculdade de Direito da Universidade de São Paulo. São Paulo: s.d., 1934.

MARINHO, Marinha Gabriela S. M. C. Norte-americanos no Brasil. Uma história da Fundação Rockefeller na Universidade de São Paulo (1934-1952). Campinas, SP: Autores Associados. São Paulo: USF, 2001.

MARTIN, Jerome. Un siècle de conseil et de psychologie: les conseillers d'orientation. Canal Psy, n. 121, p. 12-15, Septembre-Décembre, 2017.

MARTINS, Hildeberto Vieira. Uma história da psicologia em revista: retomando Mira y López. Arquivos Brasileiros de Psicologia, v. 66, n. 3, p. 5-19, 2014.

MASSIMI, Marina. Estudos históricos acerca da psicologia brasileira: uma contribuição. In: CAMPOS, Regina Helena de Freitas. (Org.). História da Psicologia: pesquisa, formação, ensino. Rio de Janeiro: Centro Edelstein de Pesquisas Sociais, 2008, p. 69-83.

MELO, Carolina Silva Bandeira de. Légitimation, application et formation: les missions scientifiques françaises au Brésil dans le domaine de la psychologie (1908-1947). 2016, 2 vol., 375/78 f. Thèse de Doctorat - École des Hautes Études en Sciences Sociales. Paris, 2016.

MONARCHA, Celso. Lourenço Filho e a organização da psicologia aplicada à educação (São Paulo 1922-1936). Brasilia: INEP/MEC, 2001.

MORAES, Carmen Sylvia Vidigal. Ações empresariais e formação profissional: Serviço Nacional de Aprendizagem Industrial. São Paulo em Perspectiva, v. 14, n.2, p.82-100, 2000.

MORAES, José Damiro. Noemy Rudolfer e a organização da escola e do mundo do trabalho nos anos 1920 e 1930. Educação e Pesquisa, São Paulo, v. 38, n.2, p. 485-497, jun. 2012. https://doi.org/10.1590/S1517-97022012000200014

MATHIESON, Louisa Campbell. O recenseamento escolar de 1920 na imprensa paulista: uma campanha cívica de combate ao analfabetismo. Educação $e$ Pesquisa, v.44, p.1-19, 2018. http://dx.doi.org/10.1590/S16784634201844181751

O PROBLEMA da regulamentação da profissão de psicologista e da formação regular de profissionais nesse gênero. Arquivos Brasileiros de Psicotécnica, n.2, v. 6, 1954, p. 45-50. Disponível em: http://abepsi.org.br/wpcontent/uploads/2011/07/1954-arquivosbrasileirosdepsicotecnica.pdf . Acesso 
em: 24 jun. 2020.

OUVRIER-BONNAZ, Régis. A psicologia em França de 1870 a 1940, de uma ciência aplicada a uma disciplina universitária. Actas de Seminários, $X V$ Semana da Associação de Estudantes da Faculdade de Psicologia e de Ciências da Educação da Universidade do Porto, n.1, v.3, 2006, 57-63.

PAICHELER-HARROUS, Geneviève. A invenção da Psicologia Moderna. Tradução Maria Helena Souza Patto e Luiz Eduardo Vasconcelos Moreira. São Paulo: Benjamin, 2018.

PETITJEAN, Patrick. Entre ciência e diplomacia: A organização da influência científica francesa na América Latina, 1900-1940. In: HAMBURGUER, Amélia Império; DANTES, Maria Amélia; PATY, Michel; PETITJEAN, Patrick. (Orgs). A ciência nas relações Brasil-França (1850-1950). São Paulo: EDUSP/FAPESP, 1996, p. 89-120.

PIÉRON, Henri. Psychologia e Psychotechnica. Publicação do Laboratório de Psychologia Experimental, Escola Normal de São Paulo, Typographia Siqueira de São Paulo. 1927. Biblioteca da Faculdade de Educação da USP, acervo "Oscar Thompson", documento n. 12402, localização 20500005213.

RETI, Ricardo. Os mestres de xadrez como objectos de estudos psychotechnicos. Coluna "No mundo enxadrístico". Correio da Manhã, 11 de dezembro de 1927, p.12.

REUCHLIN, Maurice. Naissance de la psychologie appliquée. In: REUCHLIN, Maurice. Traité de psychologie appliquée. Paris: PUF, 1971.

SÃO PAULO (Estado). Recenseamento Escolar. Relatório apresentado ao Exmo. Sr. Dr. Alarico Silveira, Secretário de Estado dos Negócios do Interior, pelo Sr. Dr. Antonio de Sampaio Dória, Diretor Geral da Instrucção Pública. São Paulo: Imprensa Official, 1920.

SATO, Leny. Psicologia, saúde e trabalho: distintas construções dos objetos "trabalho" e "organizações”. In: TRINDADE, Zeide Araújo; ANDRADE, Ângela Nobre. Psicologia e Saúde: um campo em construção. São Paulo: Casa do Psicólogo, 2003, p.167-178.

SENAI - SERVIÇO NACIONAL DA INDÚSTRIA. De homens e máquinas: Roberto Mange e a formação profissional, vol. 1 e 2. São Paulo: SENAISP/Arquivo de História Social "Edgard Leuenroth", 1991.

SILVA, Luciana Vieira; SIQUEIRA, Rogério Monteiro de. An Italian mission at 
the University of São Paulo: Science and education issues in the diplomatic relationships between Italy and Brazil in the 1930s. Les Mélanges de l'École française de Rome - Italie et Méditerranée modernes et contemporaines (MEFRIM), v. 130, n.1, p. 407-419, 2018.

SUZIGAN, Wilson. Indústria brasileira: origem e desenvolvimento. São Paulo: Hucitec/Editora da UNICAMP, 2000.

TESTES pedagógicos, pelo Prof. Baker. O ESTADO DE SÃO PAULO, São Paulo, 29 jul. 1926. Coluna "Leituras e Conferências", p. 5.

TURBIAUX, Marcel. A aptidão profissional segundo J.-M. Lahy. Trad. João Viana Jorge. Laboreal, v. XIII, n.1, p. 92-6, 2017. http://DX.DOI.ORG/10.15667/LABOREALXIIIO117MT.

WECHSLER, Solange Muglia; HUTZ, Claudio Simon; PRIMI, Ricardo. O desenvolvimento da avaliação psicológica no Brasil: Avanços históricos e desafios. Avaliaçao Psicologica: Interamerican Journal of Psychological Assessment, v. 18, n. 2, p. 121-128, 2019.

ZANETTI, Augusto. A engenharia pedagógica; taylorismo e racionalização no pensamento de Roberto Mange. 2001. 255 f. Tese (Doutorado em Educação) Universidade Estadual de Campinas/UNICAMP. Campinas, 2001.

ZANETTI, Augusto. Roberto Mange e o taylorismo. Anais do XXIII Simpósio da Associação Nacional de História, 2005. Disponível em:

https://anpuh.org.br/uploads/anais-simposios/pdf/2019-

01/1548206372_229786df44e2ad3a7636e587033e4431.pdf. Acesso em 04 mar. 2020.

LUCIANA DADICO é professora Adjunta de Psicologia na Universidade Federal de Mato Grosso e Professora de Pós-Graduação no Programa de Pesquisa em Estudos Culturais da Escola de Artes, Ciências e Humanidades da Universidade de São Paulo (EACH-USP). Doutora em Psicologia Escolar e do Desenvolvimento Humano (USP), com período sanduíche na Scuola Normale Superiore di Pisa. Pós-doutorado em Psicologia (USP), Teoria Crítica da Sociedade (Universidade da Califórnia, Berkeley) e Estudos Culturais (USP).

E-mail: ludadico@usp.br

(D) http://orcid.org/0000-0001-8577-6892 
ROGÉRIO MONTEIRO DE SIQUEIRA é professor da Escola de Artes, Ciências e Humanidades (EACH) da Universidade de São Paulo (USP) desde 2007. É livre-docente em história da ciência, pela USP, e orientador do Programa de Pós-graduação em Estudos Culturais da EACH-USP. Foi coordenador desse mesmo programa de 2012 a 2016. É vice-presidente da Sociedade Brasileira de História da Ciência (SBHC). Fez dois estágios pós-doutorais em História das ciências: em 2008, na Universidad de Sevilla, Espanha, e na Université de Paris 6, França, em 2012.

E-mail: rogerms@usp.br

(D) http://orcid.org/0000-0002-5915-0930

Recebido em: 25 de junho de 2020

Aprovado em: 30 de abril de 2021

Editora responsável: Terciane Luchese

Revista História da Educação - RHE
Associação Sul-Rio-Grandense de Pesquisadores em História da Educação - Asphe
Artigo de acesso aberto distribuído nos termos de licença Creative Commons.

